\title{
Enhancing Corrosion Resistance of High-Carbon Steel by Formation of Surface Layers Using Wastes as Input
}

\author{
Wilson Handoko *(D), Farshid Pahlevani *(i) and Veena Sahajwalla \\ School of Materials Science and Engineering, Centre for Sustainable Materials Research and Technology (SMaRT \\ Centre), University of New South Wales, Sydney, NSW 2052, Australia \\ * Correspondence: w.handoko@unsw.edu.au (W.H.); f.pahlevani@unsw.edu.au (F.P.); \\ Tel.: +61-425-958-088 (W.H.); +61-423-423-594 (F.P.)
}

Received: 30 July 2019; Accepted: 14 August 2019; Published: 16 August 2019

\begin{abstract}
Series of super-hard ceramic layers have been successfully developed on high carbon steels, with a significant improvement of corrosion resistance and hardness, without changing the original properties, which were derived from mixtures of slag (electric arc furnace), waste glass (bottles), and automotive shredder residue (ASR) plastics (polypropylene) via the single step surface modification technique. Microstructural analysis by laser scanning confocal microscopy (LSCM), crystallography analysis by X-ray diffraction (XRD), micro-level chemical analysis by scanning electron microscopy and energy dispersive spectroscopy (SEM and EDS), and depth profile surface analysis with three-dimensional chemical mapping by time-of-flight secondary ion mass spectrometry (TOF-SIMS), followed by electrochemical corrosion test by the Tafel method and hardness test-Vickers hardness measurement. Three areas have been classified, modified surface, interface, and main substrate areas as the synthesis of ceramic layers into surface of the steels that thermodynamically formed during the heat treatment process. Chemical composition analyses have revealed that generated layers consisting of chromium ( $\mathrm{Cr}$ )- and magnesium (Mg)-based compound have shown an improved corrosion resistance to $52 \%$ and hardness to $70 \%$ without modifying the initial volume fraction of constituent phases-martensite and retained austenite. These findings have substantially highlighted to the potential use of waste-integrated inputs as raw materials for production in cost-effective way, concurrently decreasing the demand on new resource for coating, alleviating the disadvantageous impact to the environment from waste disposal in landfills.
\end{abstract}

Keywords: waste source; high carbon steel; corrosion resistance; hardness; surface layer; ceramic; martensite; retained austenite

\section{Introduction}

The high carbon steel (HCS) has been dominantly used for many mining and pharmaceutical applications due to its high reliability in strength, hardness, and abrasion resistance [1-3]. However, with a mediocre level of corrosion resistance, this grade of metal alloy is susceptible to corrosion, which can increase the cost of maintenance [3]. Corrosion protection for steel is fundamental for technological importance, due to the significant used in corrosive environment. Several methods have been developed to enhance the corrosion resistance of steels, for instance, adding alloying elements [4], applying protective coating [5], and surface alloying [6]. Although these methods are relatively effective in improving corrosion resistance, they have limitations. Adding alloying elements can affect other properties [4]. Furthermore, applying protective coating can attribute to thermodynamic restriction, causing chemical reaction between the bonding of layers to substrate, which can cause cracking [5]. On the other hand, using the surface alloying method requires uniform and homogenous energy dispersion to successfully achieve a desired microstructural modification [6]. Hence, implementing 
one of the methods can increase the use of new resource, time, and cost due to complex heat treatment, high precision machinery, and inflexibility of the process.

At the same time, there is significant unreached industry requirements for further surface modification to enhance the corrosion resistance and hardness without changing the original properties. To overcome the boundary, our research used a simple and economical solution via surface modification technology, which implemented single step and low temperature heat treatment and used waste-integrated inputs as the raw materials for production of surface layers. The objective of this study is to devise a more cost-effective process to enhance the corrosion resistance and hardness properties by producing super-hard ceramic surface with $\mathrm{Cr}$ - and Mg-based layers, "interface phase" or diffused layer between ceramic and without altering the bulk properties-substrate of steels (martensite and retained austenite phases).

Nonetheless, millions of tonnes of waste slag, glass, and automotive shredder residue (ASR) from different waste streams are annually discarded in the landfills [7,8], and it has been predicted to increase every year. Disposing these wastes not only will overlook the potential use of valuable elements, such as iron $(\mathrm{Fe})$, silicon $(\mathrm{Si})$, titanium $(\mathrm{Ti})$, and carbon $(\mathrm{C})[8,9]$, but also promote the harm environment to the surrounding area due to non-decomposable materials and potential of leaching. Using these wastes as the main source has the advantages of diminishing unnecessary issuance, energy, and new resource for coating production, and alleviating negative impacts to the environment. Moreover, the presence of chromium-based compound offers a superior coating characteristic, as it provides low coefficient friction and residual stress that are used for high wear and corrosion resistance applications [10,11]. Meanwhile, the magnesium-based compound has a high-level of thermal conductivity, hardness, wear, and corrosion resistance properties, and it is commonly used in various applications [12,13].

This study is important for designing the next applications of this grade of steel, as it consolidates two major issues and defines an effective solution by transforming the wastes into protective layers through single step heat treatment process. Not only enhancement in corrosion resistance and hardness without changing the bulk properties, but also incorporating with sustainability in materials processing to minimise the wastes ending in the landfills.

\section{Materials and Methods}

\subsection{Material Preparation}

Four high carbon steel (HCS) samples with chemical compositions of $0.99 \mathrm{C}, 0.23 \mathrm{Si}$, and $0.98 \mathrm{Mn}$, $0.65 \mathrm{Cr}(\mathrm{wt} \%)$ were adopted in this study. Waste-integrated inputs, such as slag, glass, ASR (ratio 1:1:1), with composition of slag-38.7 $\mathrm{Fe}_{2} \mathrm{O}_{3}, 12.1 \mathrm{SiO}_{2}, 7.1 \mathrm{MnO}, 29.8 \mathrm{CaO}, 4.4 \mathrm{Al}_{2} \mathrm{O}_{3}, 7.0 \mathrm{MgO}, 2.0 \mathrm{Cr}_{2} \mathrm{O}_{3}$, balance $(\mathrm{wt} \%)$, which were obtained from from Electric Arc Furnace and waste glass with $71.55 \mathrm{SiO}_{2}$, $15.82 \mathrm{Na}_{2} \mathrm{O}, 9.21 \mathrm{CaO}, 3.95 \mathrm{MgO}$, balanced from bottles. These compositions have been characterised by X-ray Fluorescence (XRF) analysis. Polypropylene plastics from car bumper-ASR were used in this study and characterised by Fourier-Transform Infrared Spectroscopy (FTIR) analysis. Proposed innovative surface modification process at different heating temperature and dwelling time, sample labelling (as HCS-A, HCS-B, HCS-C, and HCS-D) in this study are presented in schematic diagram, as shown in Figure 1 with table. The $99.99 \%$ purity of Ar gas was pumped into closed chamber at $1 \mathrm{~L} / \mathrm{min}$. rate to simulate an inert condition. Four samples were successfully prepared, precisely cut to $15 \mathrm{~mm} \times 15 \mathrm{~mm} \times 3 \mathrm{~mm}$ dimension by Struers Accutom-50 (Struers, Rødovre, Denmark), grinded to 4000 grit by Struers Tegramin-30 (Struers, Rødovre, Denmark), polished up to $1 \mu \mathrm{m}$ with diamond suspension by Struers Rotopol-22 (Struers, Rødovre, Denmark), ultrasonically cleaned by Powersonic 610 (Unisonics Australia, Brookvale, Australia), dried by Struers Drybox-2 (Struers, Rødovre, Denmark), and then etched by $2 \%$ Nital solution to reveal the phases. 


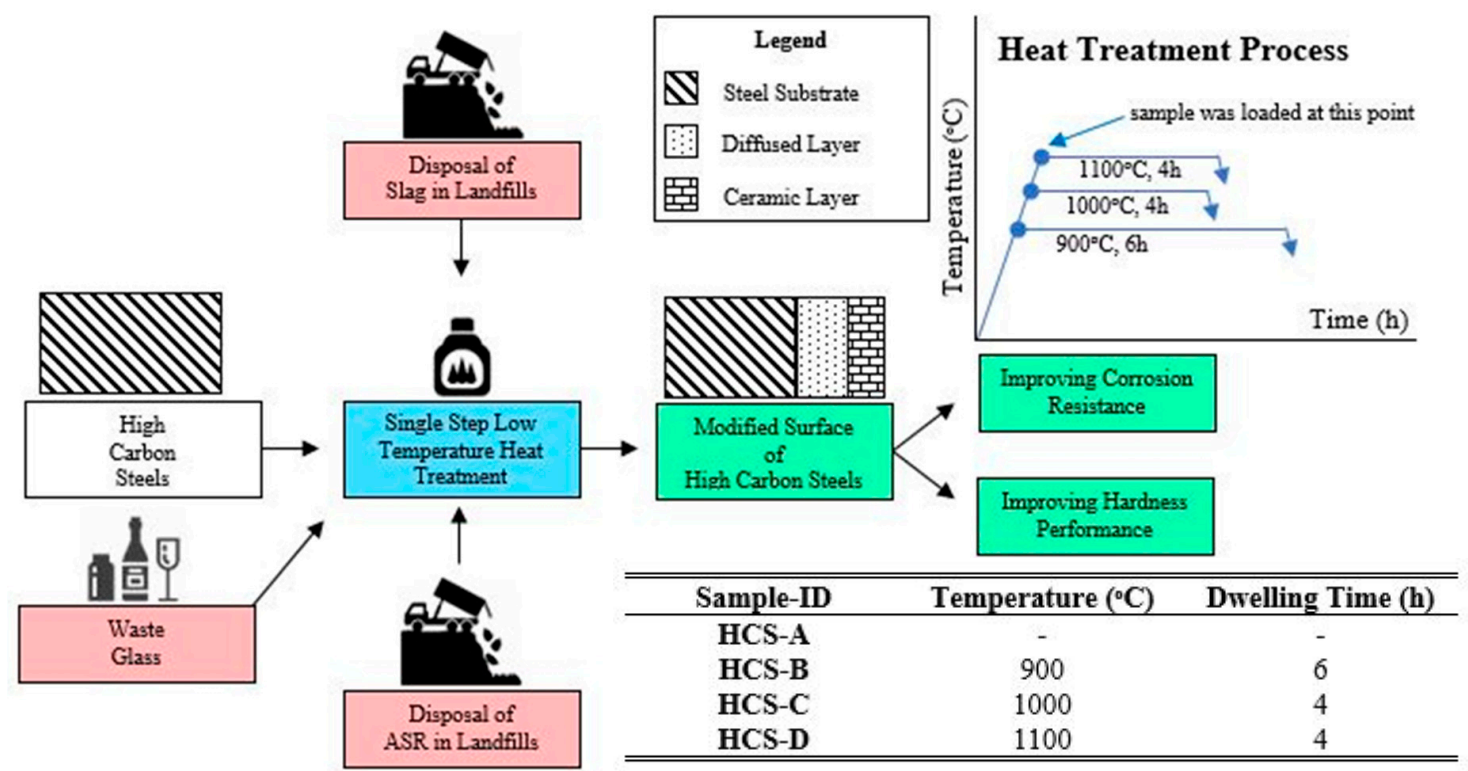

Figure 1. Schematic diagram of proposed surface modification process for formation of super-hard ceramic layer on high carbon steel (HCS) from waste-integrated inputs by single step heat treatment at different temperature and dwelling time.

\subsection{Analytical Methods}

Laser scanning confocal microscope (LSCM), Keyence VK-X250 (Keyence International, Mechelen, Belgium), and scanning electron microscope (SEM) Hitachi 3400N (Hitachi High Technologies America Inc., Schaumburg, IL, USA) were used for non-contact high-resolution imaging on the cross-sectional area of the samples, to analyse its surface topography and characteristic-main substrate, interface region, and modified surface or ceramic layer.

X-ray diffraction (XRD) analyses on the modified surface steels were carried out to observe the spectrum of the formation of surface layers and define its chemical composition, while using Empyrean (PANalytical) XRD (Malvern Panalytical Ltd., Malvern, UK), which was equipped with $\mathrm{Co}-\mathrm{K} \alpha$ radiation to avoid strong effect from fluorescence of $\mathrm{Cu}$ radiation and achieve high resolution quantitative data. Used parameters, for example, current of $40 \mathrm{~mA}$, voltage of $45 \mathrm{kV}$, recorded intensity from $2 \theta$ spectrum at angular range of $40^{\circ}$ to $130^{\circ}$, and step size of 0.02 .

Time-of-flight secondary ion mass spectrometry (TOF-SIMS) 5 spectrometer (IONTOF, Münster, Germany) was conducted for depth profile surface analysis with three-dimensional chemical maps on the region of interest-ceramic layer, by SurfaceLab software version 6.5 (IONTOF, Münster, Germany). Measurement strategy of $\mathrm{Cs}^{+}$sputter beam at $1 \mathrm{keV}$ that delivered $74.6 \mathrm{nA}$ of target current over $300 \times 300 \mu \mathrm{m}^{2}$ area, with $45^{\circ}$ incidence to the surface of sample. Dual beam mode was used with a pulsed $30 \mathrm{keV}$ for $\mathrm{Bi}^{3+}$ in positive polarity, delivering $0.322 \mathrm{pA}$ of target current over $100 \times 100 \mu \mathrm{m}^{2}$ area. The measurement of various elemental composition and concentration around a ceramic layer was carried out through energy dispersive spectrometer (EDS).

A Tafel polarisation technique was conducted by Versatile Multipotentiostat VSP-300 (EC-Lab@), Claix, France) that was equipped with EC-Lab v.11.10 software. Three different channels were connected to this instrument and a flat cell kit. Saturated calomel electrode (SCE) used for reference electrode, Pt electrode as counter electrode, and high carbon steel as working electrode. An electrolyte solution of $3.5 \mathrm{wt} \% \mathrm{NaCl}$ was used for the experiments. The tested area was $1 \mathrm{~cm}^{2}$ in open circuit potential $(\mathrm{OCP})$ for a four-hour experiment at room temperature, $24.0 \pm 0.5^{\circ} \mathrm{C}$. The obtained Tafel curves were compiled in a range of $-250 \mathrm{mV}$ and $250 \mathrm{mV}$, sweeping rate of $0.3 \mathrm{mV} / \mathrm{s}$, and bandwidth of 8 . Values of corrosion current density, $i_{\text {corr }}$ were defined through the cross path between anodic line (top section during discharging) and cathodic line (bottom section during charging) that vertically passed by corrosion potential, $\mathrm{E}_{\mathrm{corr}}$, thus, the percentage of protective efficiency, $\eta_{\mathrm{PE}}$ was calculated. 
Vickers hardness indentation method in $1 \mathrm{HV}$ parameter was demonstrated from the top area (ceramic layer) and cross-sectional area (diffused layer and steel substrate) of the samples by Struers DuraScan-20 (Struers, Darmstadt, Germany), as per standard ASTM E140.

\section{Results and Discussions}

\subsection{Microstructural Analysis}

It was performed by LSCM on a cross-sectional area of high carbon steels at a different heat treatment condition in Figure 2. At different magnification and observation area (500 $\mu \mathrm{m}$ from edge of the steel substrate), HCS-A has constituent phases that consist of martensite and retained austenite in Figure 2a,a1. The XRD analysis of HCS-B sample has demonstrated the overall evidence of Cr- and Mg-based compound that presented in the ceramic layer, which required further in-depth investigations on its chemical composition while using SEM/EDS and TOF-SIMs analysis. Similar XRD patterns occurred on sample HCS-A and HCS-C samples, in which RA represents the retained austenite phase and $\mathrm{M}$ represents the martensite phase in crystallography patterns of $2 \theta$.
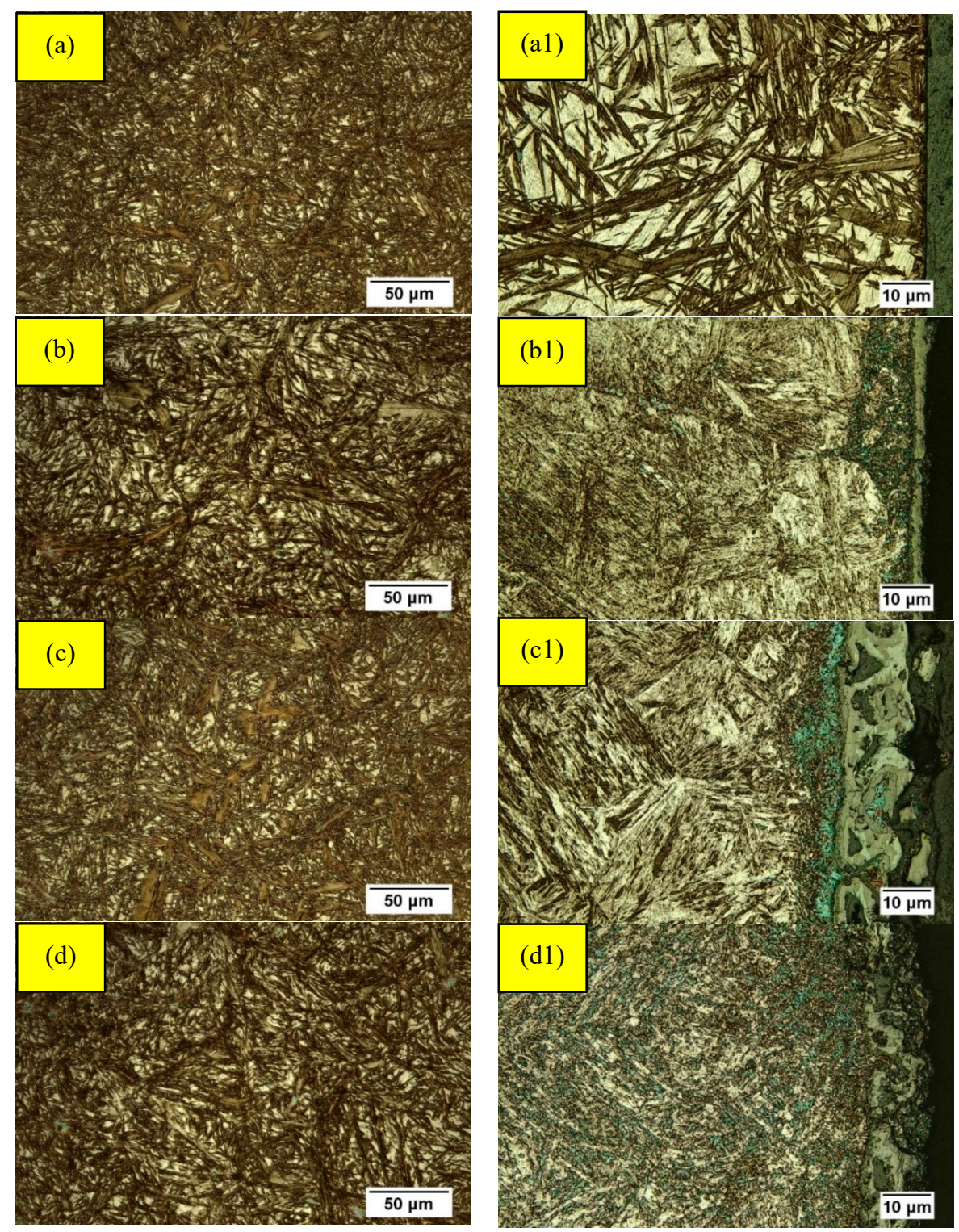

Figure 2. Cont. 


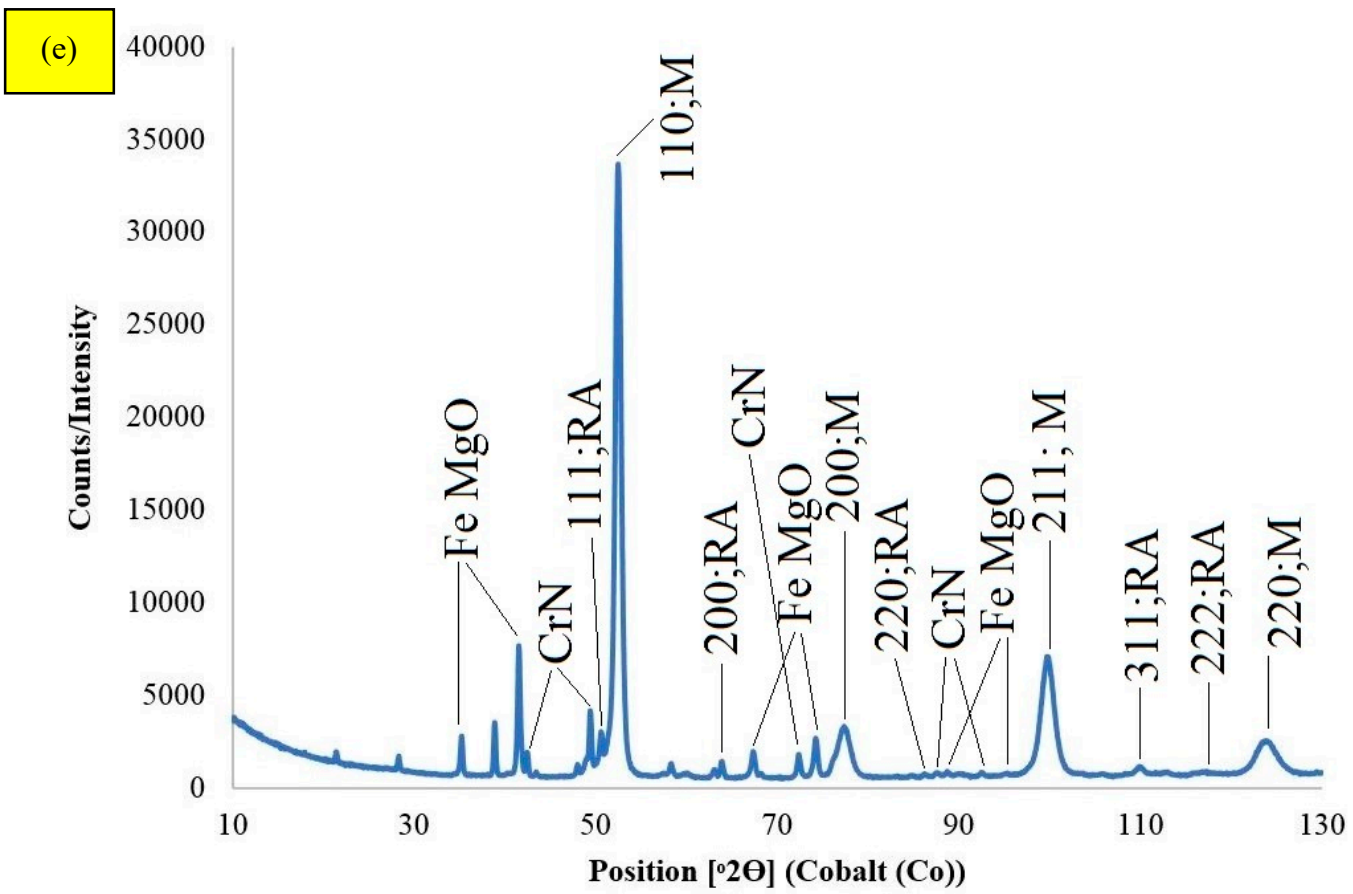

Figure 2. Laser scanning confocal microscopy (LSCM) images of cross-sectional area of main substrate on high carbon steels, which (a) HCS-A; (b) HCS-B; (c) HCS-C; and, (d) HCS-D with each interface and modified surface on (a1-d1) respectively. The (e) X-ray diffraction (XRD) analysis on the generated surface layer on sample HCS-B that demonstrate the presence of complex $\mathrm{Cr}$ - and $\mathrm{Mg}$-based compound on the ceramic layer. Where RA refers to retained austenite and $\mathrm{M}$ refers to martensite.

On the HCS-B sample, the main substrate remained unmodified in Figure $2 b$, while uniform modified surface was formed up to $5 \mu \mathrm{m}$ thickness with interface area on the edge surface as shown in Figure $2 \mathrm{~b} 1$. Whereas, HCS-C exhibited a similar feature to original bulk characteristic with generated modified surface estimated to $18 \mu \mathrm{m}$ in Figure 2c,c1 accordingly. Similarly, main substrate on HCS-D remained unchanged and modified surface accounted to $14 \mu \mathrm{m}$ in Figure 2d,d1, correspondingly. Moreover, area between ceramic layer and main substrate, laid an interface region, where it has distinctive size, shape, and volume fraction of martensite and retained the austenite phases. Meaning that it could simply perform different behaviour on corrosion resistance and hardness properties on the outer surface of steel.

With relatively smaller grain size of both phases on HCS-B and HCS-D on interface region, it has higher potential risk of corrosion attack than HCS-C. This aspect was due to higher boundary-to-boundary contact and the difference in potential energy between phases, thus, prone to boundary and pitting corrosion $[14,15]$. The other aspect was because of martensite has higher carbon (C) content than retained austenite that possessed higher iron ( $\mathrm{Fe}$ ) content, resulting martensitic phase acted as cathode, whereas the austenitic phase referred as anode, hence preferential attack on retained austenite $[14,15]$. As results, bulk properties remained unmodified with layers being formed in three waste-treated samples through the reduction process of the wastes [16] into substrate of the steel.

\subsection{Synthesis of Ceramic Layer into Steel Substrate}

This occurred during heat treatment process that led to the degradation of organic materials and the formation of $\mathrm{C}$-saturated gas from mixture of the wastes. The $\mathrm{C}-\mathrm{C}$ bond in organic materials started to disintegrate and reaction between $\mathrm{C}$ and $\mathrm{O}_{2}$ in $\mathrm{Cr}_{2} \mathrm{O}_{3}$ and $\mathrm{MgO}$ to produce $\mathrm{CO}$ and $\mathrm{CO}_{2}$. The gases have been generated in the reduction process in the system and the appliance of various wastes instead of dependency on new resources (for example transforming coal to coke to produce C-source) and adopting single step with low temperature process, has led to a more environmentally 
friendly low-cost steel that was incorporated with less energy usage, including production time, thus the cost-effectiveness can be successfully developed. In this quick process, the different surface layer that has been achieved can dramatically improve the corrosion resistance and hardness properties of HCS. Two phenomena occurred on the surface of steel: firstly, the formation of metallic phase, as the presence of $\mathrm{N}_{2}$ in ASR plastics [8,9] will cause reduction reaction of $\mathrm{Cr}_{2} \mathrm{O}_{3}$ to $\mathrm{CrN}$, including the formation of $\mathrm{CrN}$ from existing $\mathrm{Cr}$ element in steel and $\mathrm{MgO}$ to $\mathrm{Mg}_{3} \mathrm{~N}_{2}$ and $\mathrm{TiO}_{2}$ to $\mathrm{TiN}$. Secondly, the formation of oxide phases such as $\mathrm{SiO}_{2}$ and $\mathrm{CaO}$. Moreover, high carbon steel acted as catalyse and Ar represented the carrier gas for all reactions.

Chromium nitride. As $\mathrm{Cr}$ and $\mathrm{Fe}$ have excellent chemical bond, as well as low wettability angle between these elements, existing $\mathrm{Cr}$ in steel and low quantity $\mathrm{Cr}$ in slag were simply bonded on the steel substrate during exothermic reaction [17]. This enables the diffusion and production of $\mathrm{CrN}$ on surface of the steel, as presented in equations $[10,11]$, as below.

$$
\begin{aligned}
2 \mathrm{Cr}+\mathrm{N}_{2} & \rightarrow 2 \mathrm{CrN} \\
\mathrm{Cr}_{2} \mathrm{O}_{3}+3 \mathrm{C}+\mathrm{N}_{2} & \rightarrow 2 \mathrm{CrN}+3 \mathrm{CO} \\
\mathrm{Cr}_{2} \mathrm{O}_{3}+3 \mathrm{CH}_{4}+\mathrm{N}_{2} & \rightarrow 2 \mathrm{CrN}+3 \mathrm{CO}+6 \mathrm{H}_{2}
\end{aligned}
$$

Magnesium nitride. The Slag and glass contain relatively large amount of $\mathrm{Mg}$ element in which, at $900{ }^{\circ} \mathrm{C}$ and above, is in the liquid phase. The $\mathrm{Mg}$ has a good chemical bond with $\mathrm{Fe}$, and this enables the formation of $\mathrm{Mg}_{3} \mathrm{~N}_{2}$ on the steel surface possible [18], equations [12,13], as shown.

$$
\begin{gathered}
3 \mathrm{MgO}+3 \mathrm{C}+\mathrm{N}_{2} \rightarrow \mathrm{Mg}_{3} \mathrm{~N}_{2}+3 \mathrm{CO} \\
3 \mathrm{MgO}+3 \mathrm{CH}_{4}+\mathrm{N}_{2} \rightarrow \mathrm{Mg}_{3} \mathrm{~N}_{2}+3 \mathrm{CO}+6 \mathrm{H}_{2}
\end{gathered}
$$

The formation of other metallic phases, such as TiN from derived $\mathrm{TiO}_{2}$ in colour pigment of ASR for ultraviolet stabiliser, was produced during nitridation process [8,9]. Recent research has shown that the presence of $\mathrm{H}_{2}$ in the system will increase the reduction rate of metallic phases and iron acted as a catalyst for the formation of various ceramic compositions. With smaller diameter of $\mathrm{H}_{2}$ atoms and highly reactive behaviour, especially with $\mathrm{O}_{2}$, thus, its presence accelerated the reduction rate of oxides [19]. Other compounds that are present in the ceramic layer are oxide phases, such as $\mathrm{SiO}_{2}$, which are highly concentrated in glass and ASR [20]. On the other hand, $\mathrm{CaO}$ was mainly found in slag and glass composition. Interestingly, this composite behaviour of metallic and ceramic phases have been synthetically formed during the heat treatment process. A different gradient of elements on ceramic surface to substrate of the steel was presented in SEM and EDS analysis, as demonstrated in Figure 3. EDS mapping of $\mathrm{C}, \mathrm{N}, \mathrm{Fe}, \mathrm{Cr}, \mathrm{Mg}, \mathrm{Si}, \mathrm{Ca}, \mathrm{Ti}, \mathrm{O}$, and Mn elements have clearly exhibited different thickness of chemical-bonded layer into steel substrate. Further analysis on its hardness has been conducted and explained.

\subsection{SEM/EDS Analysis}

It can be observed that Cr-based layer was consistently presented underneath the Mg-based layer, in which it can act as secondary protection after $\mathrm{Mg}$-based layer has been removed by applied friction force. This is due to mainly presence of $\mathrm{Cr}$ in steel to synthetically form $\mathrm{Cr}$-based layer near the surface of steel that through selective diffusion process-exothermic reaction [17]. The composite behaviour can offer different corrosion and hardness properties of steels. Moreover, HCS-B formed a uniform and the thinnest ceramic layer that consisted of highly concentrated $\mathrm{CrN}, \mathrm{Mg}_{3} \mathrm{~N}_{2}$ and low concentration of TiN bonded to the steel substrate, Figure 3a. As the temperature increased, the concentration of Ca was substantially reduced due to its melting point being exceeded. Furthermore, the cavities-C element presented as resin of the mounted sample occurred at higher heat treatment temperature on the ceramic layer of HCS-C and HCS-D, as the gases remained trapped during volatilisation and gasification processes from the wastes [21]. These cavities can decrease the abrasion resistance 
properties of steel, as it has higher potential to wear off than the uniform characteristic of the ceramic layer on HCS-A. Despite these cavities, the thickness of super-hard ceramic was the thickest on HCS-C, as shown in Figure 3b, than all of the samples, including HCS-D in Figure 3c, in which could promote the higher-level of protection from corrosion degradation and hardness properties. However, further investigation on electrochemical and hardness properties are necessary to incorporate the microstructural analysis with chemical property results.

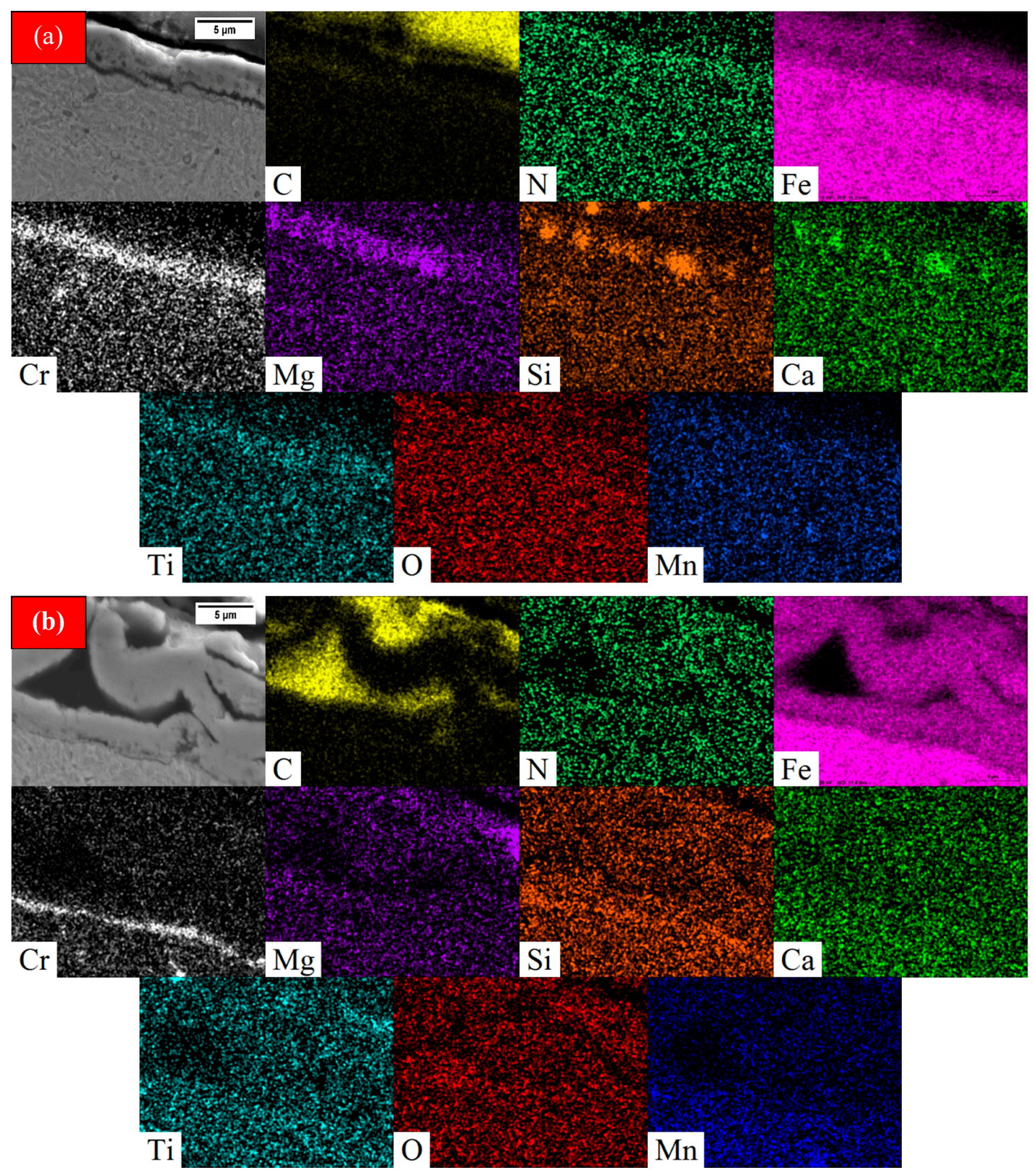

Figure 3. Cont. 


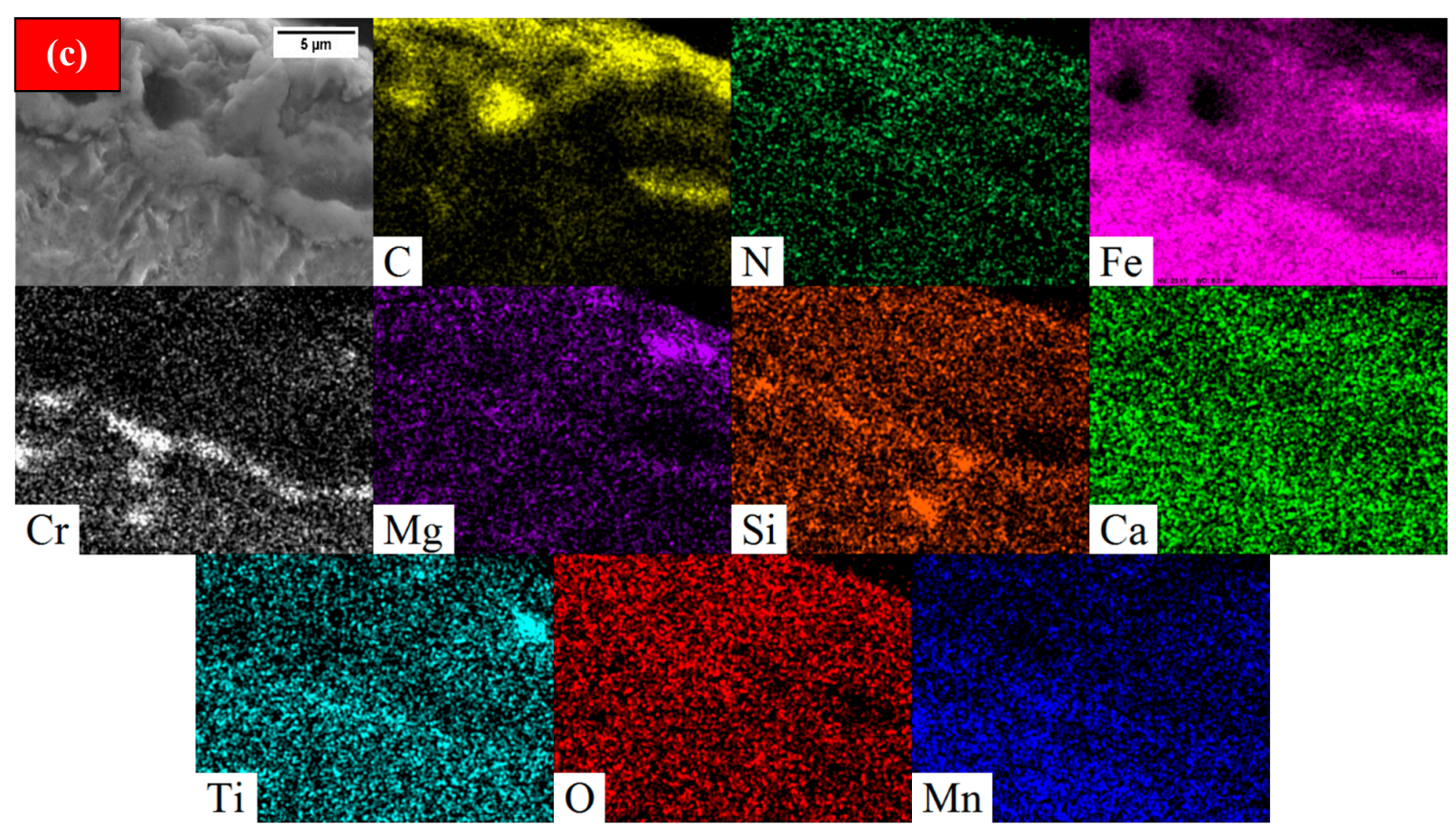

Figure 3. Energy dispersive spectrometer (EDS) intensity maps for $\mathrm{C}, \mathrm{N}, \mathrm{Fe}, \mathrm{Cr}, \mathrm{Mg}, \mathrm{Si}, \mathrm{Ca}, \mathrm{Ti}, \mathrm{O}$, and $\mathrm{Mn}$ at cross-sectional area of high carbon steels after heat treatment using waste-integrated inputs at different temperature (a) HCS-B, (b) HCS-C, and (c) HCS-D.

\subsection{XPS Analysis}

Sample HCS-D has been chosen for the further investigation on two-dimensional mapping and three-dimensional chemical composition via TOF-SIMS analysis by an ion sputtering method to acquire a desire depth profile by removing the micron size outer layers. This sample was selected for balance between better thickness of ceramic layer than HCS-B and less porous than HCS-C. From this Figure 4, the global TOF-SIMS positive ions depth profiles of $\mathrm{C}^{+}, \mathrm{N}^{+}, \mathrm{Fe}^{+}, \mathrm{Cr}^{+}, \mathrm{Mg}^{+}, \mathrm{Si}^{+}, \mathrm{Ca}^{+}$, and $\mathrm{Ti}^{+}$ions that were obtained for the ceramic layer. The results have suggested, in a good agreement with SEM/EDS chemical analysis results as well as XRD analysis, a consistent elemental composition of a strong presence on $\mathrm{Cr}, \mathrm{Mg}$, and $\mathrm{N}$-rich compounds that mainly formed in the ceramic layer.

From this graph, as the sputter time increased, the $\mathrm{Fe}^{+}, \mathrm{Cr}^{+}$, and $\mathrm{Si}^{+}$signals were gradually increased with exposure to the main substrate steel that caused this phenomenon. Whereas, the trend of ions of $\mathrm{Ca}^{+}, \mathrm{N}^{+}$, and $\mathrm{Mg}^{+}$were slightly decreased as the ion beam penetrated deep into the ceramic layer and near the main substrate of steel. The selective diffusion occurred between the bonding of the ceramic layer that was derived from different waste, into steel substrate. This bonding was believed to be due to the shift balance from thermodynamic perspective between $\mathrm{Fe}^{+}$ions that were produced from mainly slag that contained less $C$ content to higher $C$ content that already present in main substrate of the steel. $\mathrm{Cr}$ and Fe have excellent, as well as low, wettability and diffusivity; $\mathrm{Cr}$ oxide in slag that has been through reduction process in heat treatment and the presence of $\mathrm{Cr}$ in steel, bonded into steel substrate with iron, acted as catalyst during the exothermic reaction. This enables the diffusion and production of $\mathrm{CrN}$ on surface of the steel. Slag and glass contained a relatively high volume of $\mathrm{Mg}$ element, in which, at this heating temperature, it was in the liquid state. Similarly, $\mathrm{Mg}$ has good chemical bond with $\mathrm{Fe}$, and this makes the formation of $\mathrm{Mg}_{3} \mathrm{~N}_{2}$ on the steel surface possible, which is in good agreement with TOF-SIMS depth profile analysis. 
(a)
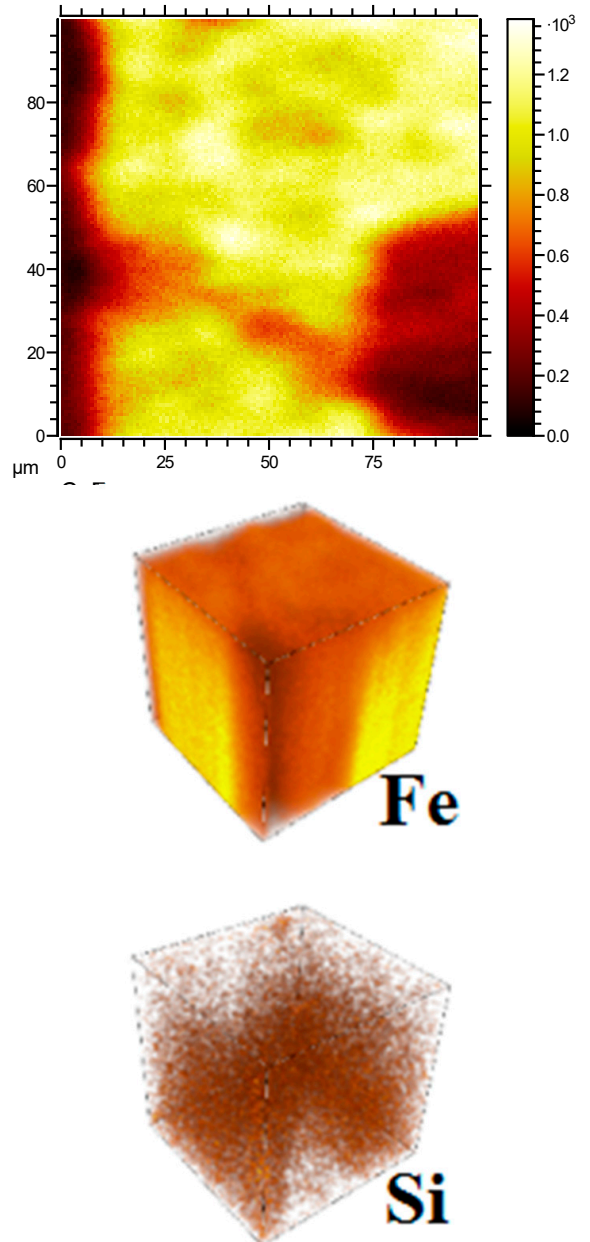
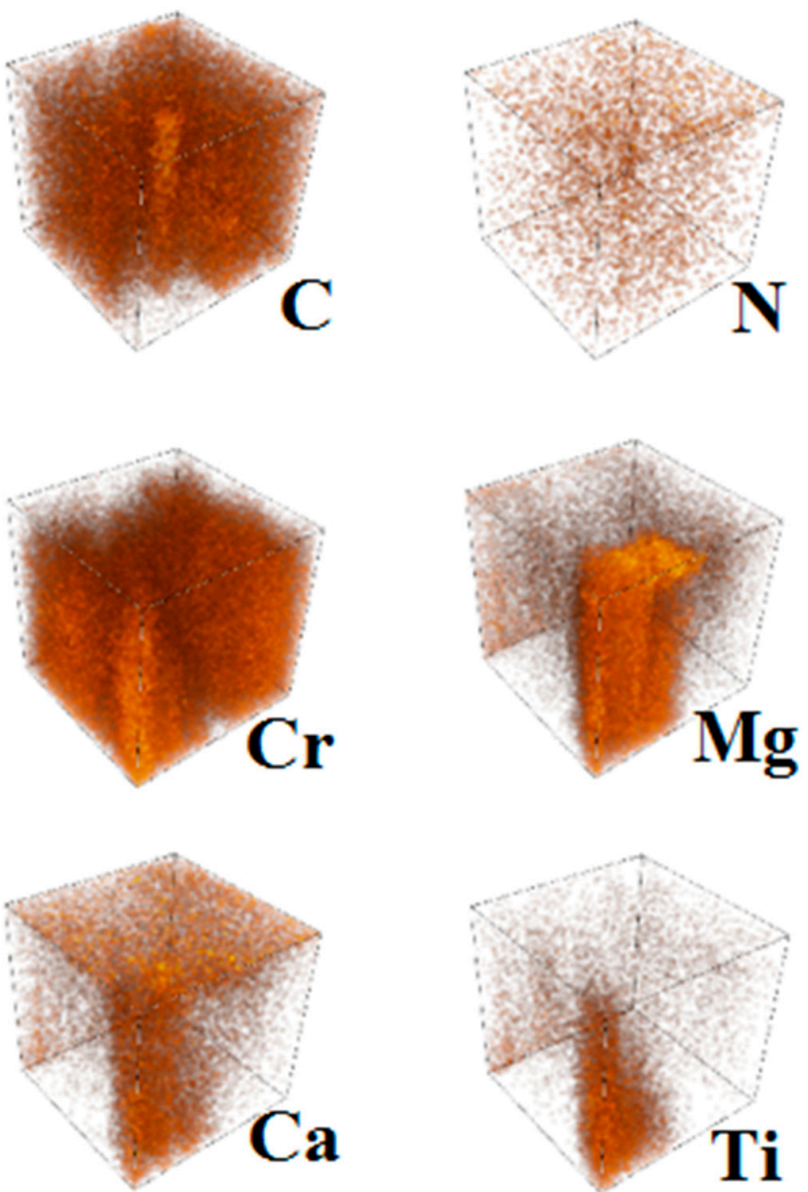

(b)

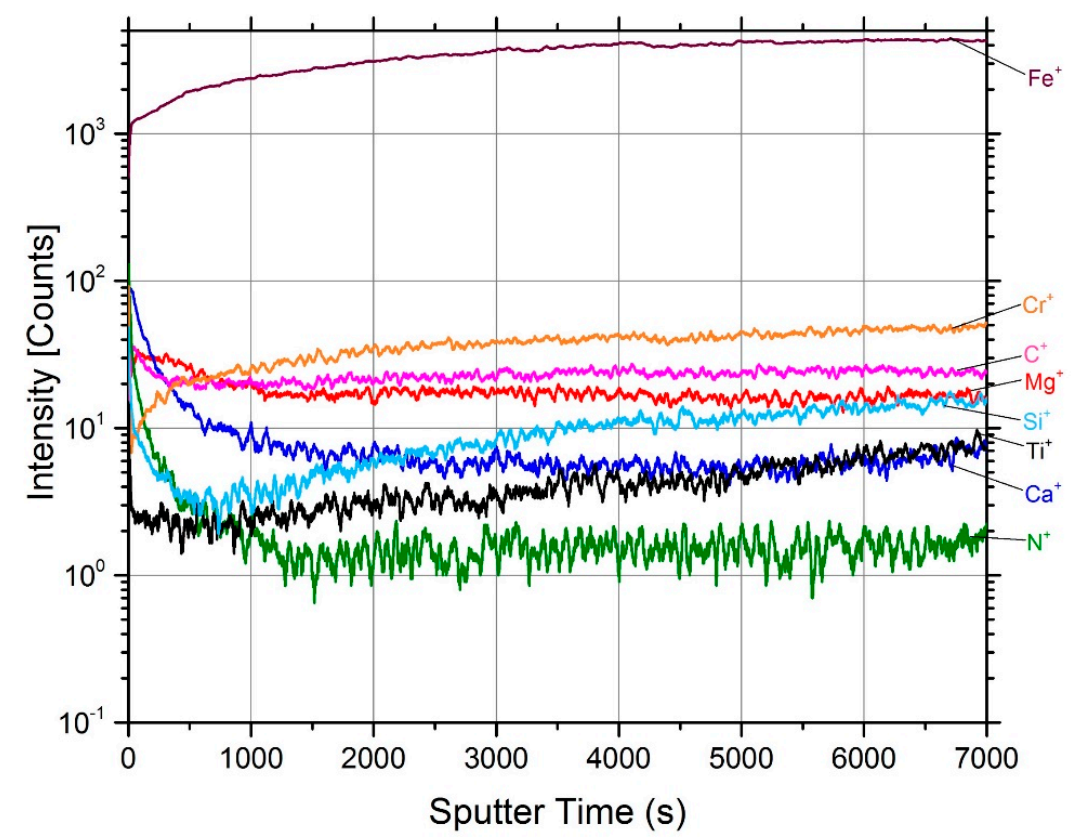

Figure 4. Time-of-flight secondary ion mass spectrometry (TOF-SIMS) (a) two-dimensional (2D) mapping and three-dimensional (3D) chemical analysis on the desire depth profile on near surface region of interest from ceramic layer to examine $\mathrm{C}^{+}, \mathrm{N}^{+}, \mathrm{Fe}^{+}, \mathrm{Cr}^{+}, \mathrm{Mg}^{+}, \mathrm{Si}^{+}, \mathrm{Ca}^{+}$, and $\mathrm{Ti}^{+}$ion signals of the HCS-D sample. The summary of $(\mathbf{b})$ intensity of each ions over sputter time graph. 


\subsection{Electrochemical Corrosion Test}

Investigation of the electrochemical corrosion properties by Tafel method was conducted to analyse the effect of generated layers on corrosion rate, as shown in Figure 5. To define improvement in corrosion resistance, lower $\mathrm{i}_{\text {corr }}$ value and more positive $\mathrm{E}_{\text {corr }}$ value toward noble side were required. Protection efficiency, $\eta_{P E}$ values were calculated against HCS-A by the standard equation [22]. As consequences, the corrosion protection efficiency contributed around $18.35 \%, 51.96 \%$ and $35.44 \%$ on HCS-B, HCS-C, and HCS-D, respectively. The protective efficiency values were obtained against the base-material (HCS-A) or before heat-treated using wastes. HCS-C possessed the highest corrosion resistance as it has the thickest coating, leading to its highest improvement. Additionally, this improvement has direct effect on the presence of $\mathrm{CrN}$ and $\mathrm{Mg}_{3} \mathrm{~N}_{2}$ in the ceramic layer, as they tend to have corrosion resistance nature. While, HCS-B has lowest protection, since its six-hour dwelling time, followed by HCS-D heat-treated at higher temperature, which was caused by volatilisation and gasification from most wastes, hence increased the decomposition rate that led to direct effect on diffusion rate and reduction reaction of metallic and oxide phases into steel substrate.

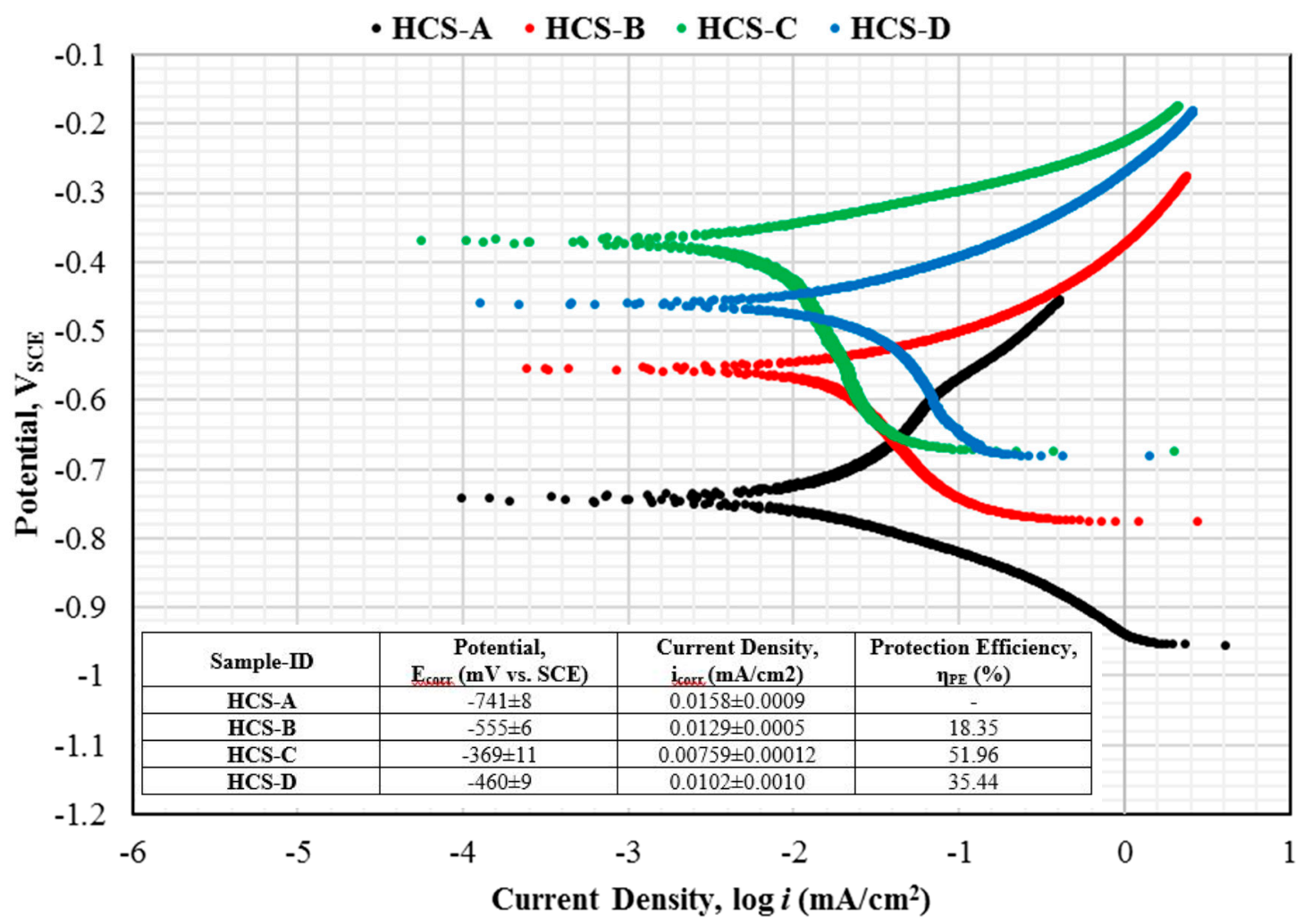

Figure 5. Comparison of Tafel extrapolation curve of studied high carbon steel samples.

\subsection{Microhardness Test}

Vickers hardness measurement was conducted on high carbon steels before and after the heat treatment process, as summarised in detail in Figure 6. The hardness of HCS-C was the highest, increased up to $1394 \mathrm{HV}$ or $69.79 \%$ and $983 \mathrm{HV}$ or $19.73 \%$ improvement on its super-hard ceramic layer from approximately $821 \mathrm{HV}$ on HCS-A. This significant increase was associated with the effect of the presence of dominant $\mathrm{Cr}$-based compound that was well-known as its interstitial compound, in which the $\mathrm{N}_{2}$ atoms occupying octahedral gaps in $\mathrm{Cr}$ lattice thus offered not only extremely high-level corrosion resistance, but also very hard nature property. Combination with $\mathrm{Mg}$-based that commonly known as its nitrides of alkaline earth metals, normally used as hard coating, offered hardness property nature in this compound, aside from the temperature and dwelling time of heat treatment on the waste-integrated input. 
$\square$ HCS-A $\square$ HCS-B $\square$ HCS-C $\square$ HCS-D

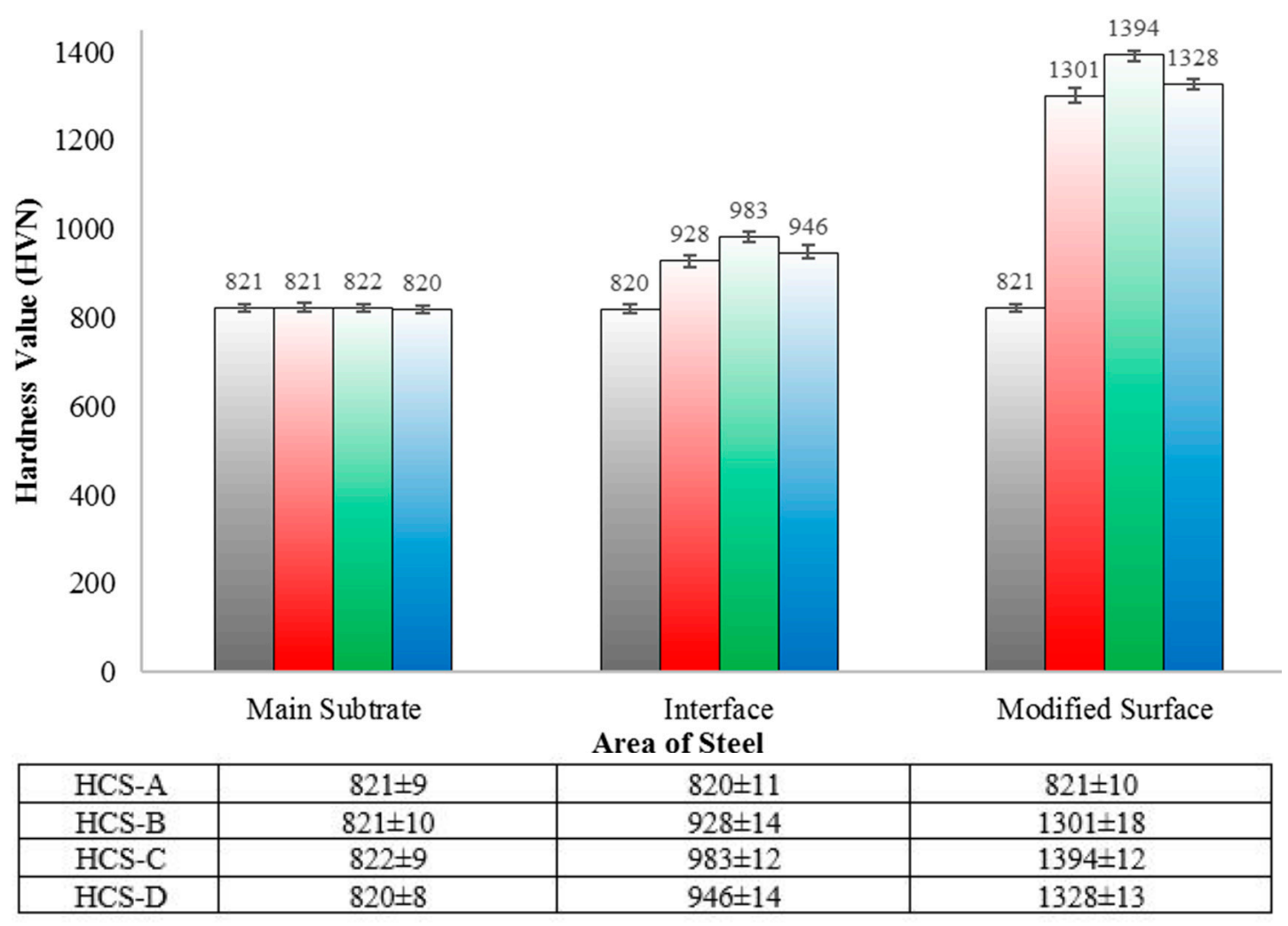

Figure 6. Summary of hardness values at in different tested area of high carbon steels.

\section{Conclusions}

The enhancement of corrosion resistance and hardness properties of high carbon steels have been successfully achieved by single step surface modification method while using waste-integrated (slag, glass and ASR) as source of inputs. At different heat treatment temperature, the ceramic layers have become a favourable outcome in an economical way of modified surface. Series of ceramic layers have been developed and its bulk properties remained unmodified through microstructural analysis by laser scanning confocal microscopy. XRD result has shown the strong presence of $\mathrm{Cr}$ - and $\mathrm{Mg}$-based compound of generated ceramic layer. The effect of a different heat treatment parameter has a direct effect on the thickness of overall ceramic layer bonded on surface of high carbon steels. This generated a super-hard ceramic layer that mainly consisted of $\mathrm{Cr}$ - and Mg-based elements that has been proved through cross-sectioned SEM/EDS analysis and in-depth TOF-SIMS depth profile chemical analysis by sputtering ions. Electrochemical analysis by the Tafel method has showed significant improvement on corrosion resistance of nearly $52 \%$ and hardness to $70 \%$ than base-material. The results highlighted a very notable potential used of various wastes as valuable resource for production that promoted cost effectiveness, simultaneously minimising the needs of additional energy and time in the manufacturing process, dependency on new resource for alloying or coating, and the alleviating negative impact to the environment from waste disposal in the landfills.

Author Contributions: W.H. designed and performed experiments and data analysis. F.P. performed experiments and critically analysed the data. V.S. supervised the study and gave recommendations to revise manuscript. W.H. wrote the manuscript and all authors analysed data, discussed the results, read and approved the final manuscript.

Funding: This research was funded by Australian Government Research Training Program (RTP) and Australian Research Council's Industrial Transformation Research Hub, grant number IH130200025 and The APC was funded by project IH130200025.

Acknowledgments: This research was supported under Australian Government Research Training Program (RTP) and Australian Research Council's Industrial Transformation Research Hub funding scheme (project IH130200025). 
We gratefully acknowledge the technical support provided by Electron Microscope Unit at Mark Wainwright Analytical Centre, UNSW Sydney.

Conflicts of Interest: The authors declare no conflict of interest.

\section{References}

1. Liu, Q.; Zhou, Q.; Venezuela, J.; Zhang, M.; Atrens, A. Hydrogen influence on some advanced high-strength steels. Corros. Sci. 2017, 125, 114-138. [CrossRef]

2. Handoko, W.; Pahlevani, F.; Hossain, R.; Sahajwalla, V. Stress-induced phase transformation and its correlation with corrosion properties of dual-phase high carbon steel. J. Manus. Mater. Process. 2019, 3, 55. [CrossRef]

3. Handoko, W.; Pahlevani, F.; Sahajwalla, V. Effect of austenitisation temperature on corrosion resistance properties of dual-phase high-carbon steel. J. Mater. Sci. 2019, 54, 13775-13876. [CrossRef]

4. Handoko, W.; Pahlevani, F.; Sahajwalla, V. The effect of low-quantity Cr addition on the corrosion behaviour of dual-phase high carbon steel. Metals 2018, 8, 199. [CrossRef]

5. Pei, X.; Noël, M.; Green, M.; Fam, A.; Shier, G. Cementitious coatings for improved corrosion resistance of steel reinforcement. Surf. Coat. Technol. 2017, 315, 188-195. [CrossRef]

6. Wu, C.; Zhang, S.; Zhang, C.; Zhang, H.; Dong, S. Phase evolution and cavitation erosion corrosion behavior of FeCoCrAlNiTi x high entropy alloy coatings on 304 stainless steel by laser surface alloying. J. Alloys Compd. 2017, 698, 761-770. [CrossRef]

7. Piatak, N.; Parsons, M.; Seal, R. Characteristics and environmental aspects of slag: A review. Appl. Geochem. 2015, 57, 236-266. [CrossRef]

8. Handoko, W.; Pahlevani, F.; Emmanuelawati, I.; Sahajwalla, V. Transforming automotive waste into TiN and TiC ceramics. Mater. Lett. 2016, 176, 17-20. [CrossRef]

9. Mayyas, M.; Pahlevani, F.; Handoko, W.; Sahajwalla, V. Preliminary investigation on the thermal conversion of automotive shredder residue into value-added products: Graphitic carbon and nano-ceramics. Waste Manage. 2016, 50, 173-183. [CrossRef] [PubMed]

10. Lu, X.; Xiang, Z. Formation of chromium nitride coatings on carbon steels by pack cementation process. Surf. Coat. Technol. 2017, 309, 994-1000. [CrossRef]

11. Liang, X.; Dodge, M.; Liang, W.; Dong, H. Precipitation of chromium nitride nano-rods on lamellar carbides along austenite-ferrite boundaries in super duplex stainless steel. Scr. Mater. 2017, 127, 45-48. [CrossRef]

12. Wang, L.; Li, Q.; Zhu, Y.; Qian, Y. Magnesium-assisted formation of metal carbides and nitrides from metal oxides. Int. J. Refract. Met. Hard Mater. 2012, 31, 288-292. [CrossRef]

13. Höche, D.; Blawert, C.; Cavellier, M.; Busardo, D.; Gloriant, T. Magnesium nitride phase formation by means of ion beam implantation technique. Appl. Surf. Sci. 2011, 257, 5626-5633. [CrossRef]

14. Handoko, W.; Pahlevani, F.; Sahajwalla, V. Corrosion behaviour of dual-phase high carbon steel-microstructure influence. J. Manuf. Mater. Process 2017, 1, 21. [CrossRef]

15. Handoko, W.; Pahlevani, F.; Sahajwalla, V. Enhancing corrosion resistance and hardness properties of carbon steel through modification of microstructure. Materials 2018, 11, 2404. [CrossRef] [PubMed]

16. Ghouleh, Z.; Guthrie, R.; Shao, Y. High-strength KOBM steel slag binder activated by carbonation. Constr. Build. Mater. 2015, 99, 175-183. [CrossRef]

17. Burks, T.; Avila, M.; Akhtar, F.; Göthelid, M.; Lansåker, P.; Toprak, M.; Muhammed, M.; Uheida, A. Studies on the adsorption of chromium (VI) onto 3-Mercaptopropionic acid coated superparamagnetic iron oxide nanoparticles. J. Colloid Interface Sci. 2014, 425, 36-43. [CrossRef]

18. Lamaka, S.; Höche, D.; Petrauskas, R.; Blawert, C.; Zheludkevich, M. A new concept for corrosion inhibition of magnesium: Suppression of iron re-deposition. Electrochem. Commun. 2016, 62, 5-8. [CrossRef]

19. Wang, Y.; Wu, J.; Xue, S.; Wang, J.; Zhang, Y.; Tang, Y. Hydrogen production by low-temperature oxidation of coal: Exploration of the relationship between aliphatic $\mathrm{C} \mathrm{H}$ conversion and molecular hydrogen release. Int. J. Hydrogen Energy 2017, 42, 25063-25073. [CrossRef]

20. Ogirigbo, O.; Black, L. Influence of slag composition and temperature on the hydration and microstructure of slag blended cements. Constr. Build. Mater. 2016, 126, 496-507. [CrossRef] 
21. Name, T.; Sheridan, C. Remediation of acid mine drainage using metallurgical slags. Miner. Eng. 2014, 64, 15-22. [CrossRef]

22. Zhu, X.; Lei, T. Characteristics and formation of corrosion product films of $70 \mathrm{Cu}-30 \mathrm{Ni}$ alloy in seawater. Corros. Sci. 2002, 44, 67-79. [CrossRef]

(c) (C) 2019 by the authors. Licensee MDPI, Basel, Switzerland. This article is an open access article distributed under the terms and conditions of the Creative Commons Attribution (CC BY) license (http://creativecommons.org/licenses/by/4.0/). 